\title{
Different clinical allergological features of Taenia solium infestation
}

\author{
Paola Lucia Minciullo ${ }^{1 *}$, Antonio Cascio ${ }^{2}$, Stefania Isola ${ }^{1}$ and Sebastiano Gangemi ${ }^{1,3}$
}

\begin{abstract}
The tapeworm Taenia (T.) solium can be responsible for two different conditions: taeniasis and cysticercosis. Helminth infections in human host cause an immune response associated with elevated levels of IgE, tissue eosinophilia and mastocytosis, and with the presence of CD4+ T cells that preferentially produce IL-4, IL-5, and IL-13. Individuals exposed to helminth infections may have allergic inflammatory responses to parasites and parasite antigens. PubMed search of human cases of allergic reactions occurring during T. solium infestation was performed combining the terms (allergy, urticaria, angioedema, asthma, anaphylaxis) with T. solium. A study was considered eligible for inclusion in the review if it reported data on patients with T. solium infestation who had signs or symptoms of allergy. In literature we found six articles reporting the association between an allergic reaction and T. solium infestation: two cases of urticaria, two cases of relapsing angioedema, one case of asthma and two cases of anaphylaxis. Despite the large diffusion of T. solium infestation, we found only a few cases of concomitant allergic reaction and the presence of Taenia in the host. The association between T. solium infestation and allergic manifestations has never been clearly demonstrated, and in absence of a well-documented causality the hypotheses are merely speculative. Therefore, the association between Taenia infection and allergy needs to be thoroughly studied to better clarify if this association may really exist and which is the pathogenetic mechanism supported.
\end{abstract}

Keywords: Allergy, Anaphylaxis, Angioedema, Asthma, Cysticercosis, Urticaria, Taenia solium

\section{Background}

The tapeworm Taenia (T.) solium can be responsible for two different conditions: taeniasis and cysticercosis. Taeniasis is infection with an adult tapeworm, while cysticercosis is infection with larval stages (of T. solium) in body tissues. Taeniasis occurs only in the human host, after ingestion of undercooked pork infected with cysticerci. In taeniasis an adult worm is present in the intestine, and the infestation is usually asymptomatic and generally recognized when segments of proglottids are found in stool specimens. Cysticercosis is caused by ingestion of food contaminated with feces, or by autoinfection. In the latter case, a human infected with adult T. solium can ingest eggs produced by that tapeworm, either through fecal contamination or, possibly, from proglottids carried

\footnotetext{
*Correspondence: pminciullo@unime.it

${ }^{1}$ School and Division of Allergy and Clinical Immunology, Department of Clinical and Experimental Medicine, University Hospital "G. Martino", Messina, Italy

Full list of author information is available at the end of the article
}

into the stomach by reverse peristalsis. Once eggs are ingested, oncospheres hatch in the intestine invade the intestinal wall, and migrate to striated muscles, as well as the brain, liver, and other tissues, where they develop into cysticerci. Cysticercus consists of a fluid-filled bladder elongate and oval, measuring 5-15 $\mathrm{mm}$ with a single protoscolex [1-3]. Cysticercosis of the human nervous system, called neurocysticercosis, may cause different clinical manifestations based on the characteristics of the parasites and the inflammatory response of the host. The intraparenchymal neurocysticercosis mainly causes seizures, whereas the subarachnoid infection with parasite infiltration cause hydrocephalus that may be fatal [4].

Diagnosis of cysticercosis is based on a combination of clinical presentation, imaging findings, history of exposure, and serologic testing as the detection of IgG antibodies to T. solium using an ELISA technique. In neurocysticercosis the neuroimaging techniques are considered the gold standard for the diagnosis. However, the detection of specific antibodies against T. solium 
cysticercal antigens in cerebrospinal fluid may be a useful adjunctive diagnostic test. A high rate of patients with neurocysticercosis presents specific IgE and IgG (especially IgG4) that is indicative of intrathecal antibody production [5].

The human immune response to helminth infections is associated with several immunomodulatory mechanisms that can have different and sometime opposite consequences. Asymptomatic carriers often present immunologic hyporesponsiveness and altered cytokine profiles favoring Interleukin (IL)-4 over inflammatory mediators such as IFN- $\gamma$ and with a prominent role played by IL-10 and TGF- $\beta$. On the contrary, patients who develop a symptomatic disease, present loss of the immune tolerance with predominance of Th1 and Th17 responses.

Dendritic cell antigen presentation, B cell antibody production, and epithelial cell alarmin release are other pathways of immune activation suppressed during helminth infection. On the contrary, $\mathrm{T}$ regulatory (Treg) and Breg cell differentiation is induced.

Thus, the immunomodulation caused by helminth infection can be useful for the host in protecting from allergic, autoimmune and inflammatory diseases, but, at the same time could be dangerous in reducing tumor immunosurveillance, depending on the characteristics of the parasite, the clinical course of the subject and the chronicity of infection [6].

The inverse association between helminth infection and allergy, first postulated by Bell in 1996 [7] is, today, largely assumed. The global increase in allergy especially in urban areas has led researchers to propose a modified hygiene hypothesis in which the decline in helminth infections is associated with an increase in allergic diseases [8].

However, very little data are available to explain how helminth infection might protect against allergy.

Allergy and helminths induce strongly Th2-skewed responses associated with cytokines such as IL-4, IL-5, and IL-13, with mastocytosis, eosinophilia, and antibody class-switching to produce IgE. However, the two conditions are completely different. Allergy occurs in predisposed people and is due to a polygenic disorder associated with Th2 responses and IgE expression, whereas the Th2 activation during helminth infection is a normal physiological reaction. Moreover, this response is moderated by helminths with the induction of Treg and Breg cells and the production of immunoregulatory cytokines and IgG4 that contrast IgE [9].

However, some helminth infections, especially by Ascaris lumbricoides and Anisakis simplex are associated with an increased incidence of allergic diseases, such as asthma, allergic rhinoconjunctivitis, atopic dermatitis, chronic urticaria, until to anaphylaxis [10-14]. This is probably due to a cross-reactivity between helminth proteins, as tropomyosin, and specific allergens, especially in A. lumbricoides infection $[9,15]$.

The aim of our study was to depict the different clinical allergological features of T. solium infestation.

\section{Literature review}

PubMed search of human cases of allergic reactions occurring during $T$. solium infestation was performed combining the terms (allergy, urticaria, angioedema, asthma, anaphylaxis) with $T$. solium. A study was considered eligible for inclusion in the review if it reported data on patients with $T$. solium infestation who had signs or symptoms of allergy.

\section{Results}

In literature we found six articles reporting the association between an allergic reaction and T. solium infestation: two cases of urticaria, two cases of relapsing angioedema, one case of asthma and two cases of anaphylaxis (Table 1).

\section{Urticaria}

Gupta et al. [16] described a case of a 44-year-old woman with a history of urticaria of 1 month duration. No relevant causes of urticaria were established. The patient was treated with antihistamines with a partial response. Subsequently, she presented a painful swelling over right cheek treated with antibiotics without resolution. The patient presented also mild eosinophilia. Ultrasonography on the swelling region revealed the presence of intramuscular cysticercosis with surrounding phlegmon. The woman was treated with albendazole $15 \mathrm{mg} / \mathrm{kg}$ for 1 month, initially associated to steroids to reduce inflammatory response. After treatment the Authors observed a reduction in the size of the swelling with no more

Table 1 Different allergic manifestation associated to Taenia solium infestation

\begin{tabular}{|c|c|c|c|c|}
\hline $\begin{array}{l}\text { Allergic mani- } \\
\text { festation }\end{array}$ & Sex & Age (years) & Nationality & Reference \\
\hline Urticaria & Female & 44 & Indian & Gupta et al. [16] \\
\hline $\begin{array}{l}\text { Urticarial vas- } \\
\text { culitis }\end{array}$ & Male & 36 & Ecuadorian & $\begin{array}{l}\text { Shaigany et al. } \\
\text { [17] }\end{array}$ \\
\hline \multirow[t]{2}{*}{ Angioedema } & Female & 2 & Italian & $\begin{array}{l}\text { Accomando et al. } \\
\text { [18] }\end{array}$ \\
\hline & Male & 4 & Italian & \\
\hline Asthma & Female & 35 & Mexican & $\begin{array}{l}\text { Rodríguez Orozco } \\
\text { [19] }\end{array}$ \\
\hline \multirow[t]{2}{*}{ Anaphylaxis } & Male & 20 & Indian & Singh et al. [20] \\
\hline & Male & 26 & Italian & Minciullo et al. [1] \\
\hline
\end{tabular}


evidence of active cysticercosis in the muscle and also the resolution of urticaria.

A case of urticarial vasculitis associated to neurocysticercosis has been reported [17]. A 36-year-old man presented afebrile seizure and a 3- to 4-month history of intermittent pruritic widespread rash associated with a burning sensation. He had edematous plaques and scattered erythematous papules on both posterior thighs. Skin biopsy showed leukocytoclastic vasculitis, leading to a diagnosis of urticarial vasculitis. The patient presented a cystic lesion in his brain with degenerating cysticercus. Despite the serum antibody testing for cysticercosis was negative and cysticercosis immunoglobulin (Ig)G antibodies had undetectable levels in cerebrospinal fluid, the clinical feature, the exam of the cystic lesion and the MRI images fulfilled the criteria of neurocysticercosis. The patient was treated with albendazole $400 \mathrm{mg}$ twice daily and his urticarial vasculitis resolved within a few days.

\section{Angioedema}

Two cases of angioedema related to cysticercosis have been reported by the same Authors [18]. The patients, a 2-year-old female and a 4-year-old male, presented a history of relapsing and migrant angioedema in the upper and lower limbs and in the body trunk and the female patient in the genital region also. The angioedema was associated to prurigo and rash. Blood and stool parasitological exams were normal except for hypereosinophilia; skin prick test for the most common inhalant and food allergens was negative. Test for cysticercosis showed high positivity, however, no presence of $T$. solium cyst was found. Treatment with albendazole $5 \mathrm{mg} / \mathrm{kg}$ every $8 \mathrm{~h}$ for 4 months led to normal levels of eosinophils and to the disappearance of angioedema.

\section{Asthma}

A case of asthma exacerbation related to neurocysticercosis has been reported by Rodriguez Orozco [19]. A 35 -year-old female with a 2 years history of mild asthma presented headache, nausea, vomiting and an episode of convulsion in the last 3 months. The electroencephalogram and the neurological evaluation were normal. During the last 2 months the patient presented nocturnal dyspnea, wheezing and a worsening of headache and nausea and she needed hospitalization. She was treated with inhalant corticosteroids and beta-agonists, antileukotrienes and oral corticosteroids. Because of headache and nausea persisted, the patient underwent cerebral tomography that showed the presence of two parenchymal cysts. One was a colloidal cyst interpreted as cyst with a dying parasite, the other one as a dead cyst. The Author concluded that the neurological manifestations were linked to the parasite death. Since asthma exacerbation and neurological symptoms appearance were concomitant, the Author hypothesized that the two entities were related, however, it is difficult to establish in this case if neurocysticercosis is a concomitant event or a trigger factor for asthma exacerbation.

\section{Anaphylaxis}

Two case of anaphylaxis related to T. solium infestation have been reported $[1,20]$. The first was a 20 -year-old man who presented with sudden onset of transient generalized urticarial rashes, hypogastric pain that spread to the whole of the abdomen, vomiting, watery diarrhoea and fever of $6 \mathrm{~h}$ duration. He also exhibited tachycardia, hypotension, diffuse abdominal tenderness, and rigidity. A diagnosis of appendicular perforation with pelvic collection was made and exploratory laparotomy was normal except for the presence of colourless, odourless gelatinous material in the pelvis. The appendix was histopathologically normal and the histopathological examination of this fluid showed cysticercosis presence. The patient was treated with albendazole $15 \mathrm{mg} / \mathrm{kg}$ for 28 days and no other signs of Taenia infestation were present in the follow-up.

The Authors hypothesized a rupture of a cyst in the peritoneal cavity that led to the anaphylactic reaction and the gelatinous content of the cyst caused a peritoneal inflammation mimicking the secondary peritonitis of appendicular perforation [20].

A case of fatal anaphylaxis has been reported by our group [1]. A 26-year-old male died during sleep and death did not seem linked to any previous known diseases. The cadaveric and histologic examinations and the necroscopy concluded that the cause of death was anaphylactic reaction. Specifically, swelling of the larynx, mucous plugging in the airways, pulmonary emphysema, visceral congestion, and splenic eosinophilia supported an allergic reaction. Moreover, in the intestinal loops several meters of a tapeworm with a long series of proglottids were found the worm was identified as T. solium.

The most common causes of anaphylaxis (drugs, foods, insect sting) were excluded by interviews with the man's relatives, external examination of the body, and cadaveric examination.

The Authors hypothesized an autoinfection of larval forms by ingestion of eggs present on the man's dirty hands or by reverse peristalsis had occurred and the larval forms developed into cysticercosal cysts. The rupture of a unknown cyst may have triggered the anaphylaxis. At the time of necroscopy, cysticercosal cysts were not searched in the examined tissues, but the presence of $T$. solium in the intestine, the pathologic findings at autopsy, and the absence of other possible causes of anaphylaxis 
make the association between anaphylaxis and cysticercosis plausible.

\section{Discussion}

The association between allergic diseases, especially urticaria, and infectious diseases has been discussed for $>100$ years [11]. Several chronic persistent bacterial [21], viral [22], parasitic [10, 14] infections have been suspected to trigger allergic symptoms, ranging from urticaria to anaphylaxis.

Taenia solium infestation is endemic in countries in Sub-Saharan Africa, Latin America and Asia where conditions such as inadequate hygiene, poor sanitary conditions, open defecation, free roaming pigs and poverty permit the transmission of the disease [23]. However, three recent reviews indicate that autochthonous human T. solium taeniasis/cysticercosis may be possible in Europe [24-26], but current peer reviewed literature is biased towards Western Europe [27].

In this review we reported allergic manifestations related to Taenia infestation. Despite the large diffusion of $T$. solium infestation, we found only seven cases of concomitant allergic reaction and the presence of Taenia in the host. The clinical allergological manifestations reported in these cases are various, including urticaria, angioedema, asthma and anaphylaxis. Moreover, it is interesting to highlight that two cases are reported from India [16, 20], one from Mexico [19], one from USA but the patient was from Ecuador [17], and three from Italy $[1,18]$.

The association between T. solium infestation and allergic manifestations has never been clearly demonstrated, therefore, in absence of a well-documented causality the hypotheses are merely speculative. In some cases the connection between the infection and the allergic reaction is supported by the resolution of the allergic symptoms after surgery and albendazole treatment [16-18]; in other cases it is uncertain if there was just a coexistence of Taenia infection and allergy or if parasite infection was a trigger factor for allergic manifestations.

In any case, the rarity of the co-occurrence of the two entities remains unclear, since helminth infections are usually associated with low rate of allergies. However, in some infections (especially A. lumbricoides and A. simplex), allergic diseases are increased; this is sometime linked to a cross-reactivity between worm proteins and specific allergens, especially in A. lumbricoides infection $[9,15]$. Nevertheless, this mechanism has not been observed in Taenia infection.

Therefore, the association between Taenia infection and allergy needs to be thoroughly studied to better clarify if this association may really exist and which is the pathogenetic mechanism supported.

\section{Abbreviations}

T:: Taenia; Ig: immunoglobulin; IL: interleukin; IFN-ץ: interferon-ү; Th: T helper; Treg: T regulatory cells; Breg: B regulatory cells.

\section{Authors' contributions}

PLM and SG made substantial contributions to conception and design of this review and participated in critical revision and drafting of final version of the manuscript. AC and SI participated in literature search, acquisition of data and manuscript writing. All authors read and approved the final manuscript.

\section{Author details \\ ${ }^{1}$ School and Division of Allergy and Clinical Immunology, Department of Clini- cal and Experimental Medicine, University Hospital "G. Martino", Messina, Italy. ${ }^{2}$ Department of Health Promotion Sciences and Mother and Child Care "G. D'Alessandro", University of Palermo, Palermo, Italy. ${ }^{3}$ Institute of Applied Sci- ences and Intelligent Systems (ISASI), Messina Unit, Messina, Italy.}

\section{Acknowledgements}

Not applicable.

\section{Competing interests}

The authors declare that they have no competing interests.

Received: 28 October 2016 Accepted: 29 November 2016 Published online: 07 December 2016

\section{References}

1. Minciullo PL, Ventura Spagnolo E, Cascio A, Cardia G, Gangemi S. Fatal anaphylactic shock and Taenia solium infestation: a possible link? Ann Allergy Asthma Immunol. 2009;103:449-50.

2. Markel EK, Voge M, John DT. Medical parasitology. 7th ed. Philadelphia: WB Saunders Co; 1992. p. 226-60.

3. Garcia HH, Gonzales AE, Evans CA, Gilman RH. Taenia solium cysticercosis. Lancet. 2003;362:547-56.

4. Garcia HH, Rodriguez S, Friedland JS, Cysticercosis Working Group in Peru. Immunology of Taenia solium taeniasis and human cysticercosis. Parasite Immunol. 2014;36:388-96.

5. Suzuki LA, Rossi CL. Evaluation of cysticercus-specific lgG (total and subclasses) and lgE antibody responses in cerebrospinal fluid samples from patients with neurocysticercosis showing intrathecal production of specific lgG antibodies. Arq Neuropsiquiatr. 2013;71:106-9.

6. Maizels RM, McSorley HJ. Regulation of the host immune system by helminth parasites. J Allergy Clin Immunol. 2016;138:666-75.

7. Bell RG. IgE, allergies and helminth parasites: a new perspective on an old conundrum. Immunol Cell Biol. 1996;74:337-45.

8. Rook GAW. Review series on helminths, immunemodulation and the hygiene hypothesis: the broader implications of the hygiene hypothesis. Immunology. 2009;126:3-11.

9. Fitzsimmons CM, Falcone FH, Dunne DW. Helminth allergens, parasite-specific lgE, and its protective role in human immunity. Front Immunol. 2014;5:61.

10. Wördemann M, Diaz RJ, Heredia LM, et al. Association of atopy, asthma, allergic rhinoconjunctivitis, atopic dermatitis and intestinal helminth infections in Cuban children. Trop Med Int Health. 2008;13:180-6.

11. Wedi B, Raap U, Wieczorek D, Kapp A. Urticaria and infections. Allergy Asthma Clin Immunol. 2009;5:10.

12. Oberholzer $C$, Nüesch $R$, Häusermann P. Urticaria and parasites: case report and general view over the most common pathogens of chronic urticaria. Praxis. 2007;96:865-70.

13. Ronellenfitsch U, Bircher A, Hatz C, Blum J. Parasites as a cause of urticaria. Helminths and protozoa as triggers of hives? Hautarzt. 2007:58(133-134):136-41.

14. Minciullo PL, Cascio A, David A, Pernice LM, Calapai G, Gangemi S. Anaphylaxis caused by helminths: review of the literature. Eur Rev Med Pharmacol Sci. 2012;16:1513-8.

15. Santiago HC, Bennuru S, Boyd A, Eberhard M, Nutman TB. Structural and immunologic cross-reactivity among filarial and mite tropomyosin: implications for the hygiene hypothesis. J Allergy Clin Immunol. 2011:127:479-86. 
16. Gupta S, Gupta S, Mittal A, Mahendra A, Aggarwal A, Batra R, et al. A rare manifestation of cysticercosis infestation. Acta Med Indones. 2004;46:54-7.

17. Shaigany S, Dabela E, Teich AF, Husain S, Grossman ME. Resolution of urticarial vasculitis after treatment of neurocysticercosis. J Am Acad Dermatol. 2015;72:e32-3.

18. Accomando S, Caserta M, Trizzino A, Amato GM. Two strange cases of hypereosinophilia and child's relapsing angio-oedema. Pediatr Med Chir 2003;25:367-9.

19. Rodríguez Orozco AR. Neurocysticercosis and asthma. Triggering or concomitant situation. Rev Alerg Mex. 2004;51:36-8.

20. Singh RB, Pavithran NM, Bakshi N. Intraperitoneal rupture of cysticercosal cyst mimicking appendicular perforation. Trop Doct. 2006;36:180-1.

21. Minciullo PL, Cascio A, Barberi G, Gangemi S. Urticaria and bacterial infections. In: Allergy and asthma proceedings, vol. 35, no. 4. Cleveland: OceanSide Publications, Inc.; 2014. p. 295-302.

22. Imbalzano E, Casciaro M, Quartuccio S, Minciullo PL, Cascio A, Calapai $G$, et al. Association between urticaria and virus infections: a systematic review. In: Allergy and asthma proceedings, vol. 37, no. 1. Cleveland: OceanSide Publications, Inc:; 2016. p. 18-22.
23. Coral-Almeida M, Gabriël S, Abatih EN, Praet N, Benitez W, Dorny P. Taenia solium human cysticercosis: a systematic review of sero-epidemiological data from endemic zones around the world. PLoS Negl Trop Dis. 2014;9:e0003919.

24. Del Brutto $\mathrm{OH}$. Neurocysticercosis in Western Europe: a re-emerging disease? Acta Neurol Belg. 2012;112:335-43.

25. Zammarchi L, Strohmeyer M, Bartalesi F, Bruno E, Muñoz J, Buonfrate $\mathrm{D}$, et al. Epidemiology and management of cysticercosis and Taenia solium taeniasis in Europe, systematic review 1990-2011. PLoS ONE. 2013;8:e69537.

26. Fabiani S, Bruschi F. Neurocysticercosis in Europe: still a public health concern not only for imported cases. Acta Trop. 2013;128:18-26.

27. Devleesschauwer B, Allepuz A, Dermauw V, Johansen MV, LaranjoGonzález M, Smit GS, et al. Taenia solium in Europe: still endemic? Acta Trop. 2015. doi:10.1016/j.actatropica.2015.08.006.

\section{Submit your next manuscript to BioMed Central and we will help you at every step:}

- We accept pre-submission inquiries

- Our selector tool helps you to find the most relevant journal

- We provide round the clock customer support

- Convenient online submission

- Thorough peer review

- Inclusion in PubMed and all major indexing services

- Maximum visibility for your research

Submit your manuscript at www.biomedcentral com/submit 